\title{
INVESTIGACIÓN/RESEARCH
}

Recibido: 28/06/2010---Revisado: 29/07/2010

Aceptado: 29/09/2011---Publicado: 15/03/2011

\section{INTRODUCCIÓN A LA EDUCACIÓN MEDIÁTICA INFANTIL: EL DISEÑO DEL STORYBOARD}

Jacqueline Sánchez-Carrero ${ }^{1}$ : Universidad de Huelva. España.

jsanchezcarrero@gmail.com

\section{RESUMEN}

Los niños del siglo XXI son llamados nativos digitales y precisamente por ello requieren de una educación práctica que les ayude a comprender y aprovechar los contenidos de las diferentes pantallas a las que tienen acceso. Esta comunicación profundiza en el valor del Storyboard como instrumento clave en la enseñanza de la educación audiovisual para niños. Profundiza en la experiencia de los talleres audiovisuales impartidos por los autores a niños en Venezuela y en España. Analiza además otras prácticas provenientes de escuelas de cine y televisión destinadas a los chicos en distintas partes del mundo. El método de investigación ha sido el análisis gráfico y de contenido de las historias propuestas por los pequeños aprendices. El Storyboard es una herramienta útil no sólo desde el punto de vista técnico identificación de planos y narraciones- sino también desde el enfoque del guión, pues el niño detecta más claramente el diseño de los personajes - ¿quién hace y qué hace?y la transmisión de contenidos - ¿qué es lo que estoy tratando de difundir?- lo cual se verá reflejado en su documento audiovisual final. En esta comunicación se describen los nuevos softwares que, aunque tienen la misma función final, han modernizado la forma de elaboración del guión gráfico a través del ordenador.

PALABRAS CLAVE: Storyboard - Educación mediática - Educación - Televisión Niños.

\section{Autor Correspondiente:}

Jacqueline Sánchez-Carrero: Universidad de Huelva. España

Correo: jsanchezcarrero@gmail.com 


\title{
INTRODUCTION TO MEDIA LITERACY FOR CHILDREN: THE STORYBOARD DESIGN
}

\begin{abstract}
Children of the 21st century are called digital natives, and for that reason they need a practical education that helps them understand and exploit the contents of the different screens open to them. This work explores the value of Storyboard as a key tool in teaching media literacy to children. It builds on the experience of the audiovisual workshops for children given by the authors in Venezuela and Spain. It also examines other practices from film and television schools for children in different parts of the world. The research method was the mapping and content of the stories suggested by the young learners. Storyboard is a useful tool not only from a technical standpoint - identification of drawings and narratives - but also from the viewpoint of the script - as the child more clearly detects the character profile: who does what and what does he do? As well as the transmission of content: what is it that I am trying to get across? All this is reflected in the final audiovisual document. This work will also examine new software which, although having the same end function, has modernized computer storyboard development.
\end{abstract}

KEY WORDS: Storyboard - media literacy - education - television - children.

\section{INTRODUCCIÓN}

\section{1 Importancia del Storyboard en la educación audiovisual}

En el año 2006 Ken Robinson, especialista en educación e innovación, señaló en una conferencia que la escuela mata la creatividad de los niños porque potencia habilidades que se han devaluado. Hoy todavía esa afirmación produce debate. Una de las estrategias que se utilizan en la educación mediática es hacer uso de las habilidades creativas del niño para lograr su comprensión de la narrativa audiovisual. En la alfabetización audiovisual buscamos que se acerquen al aprendizaje de los medios desarrollando su percepción, su capacidad de expresión y sobre todo su creatividad.

Si observamos las acciones de los niños ante el medio audiovisual nos daremos cuenta de que están apropiándose de él desde hace varios años. Primero lo hicieron como objeto frente a la pantalla del cine y la televisión, es decir, como actores, cantantes, bailarines o participantes de concursos de diversa índole. Posteriormente, los niños comenzaron a adueñarse del rol que hasta el momento sólo jugábamos los adultos: ser productor audiovisual. Hoy en día, gracias al medio digital, los niños y adolescentes manejan la cámara de vídeo, escriben guiones e incluso editan sus propias historias, a menudo convertidas en cortometrajes. Y es en este papel, el que 
está detrás de la cámara, en el que el niño comienza a reflejar su forma de pensamiento y su propia visión del mundo.

\section{METODOLOGÍA}

La metodología empleada es la propia de la analítica textual combinada con el estudio de caso.

Los requisitos para elaborar un Storyboard son, en realidad, muy simples: lápiz, papel e imaginación. Algunos acuden a programas como el Power Point que facilita la tarea. No obstante, cada día aumentan las propuestas tecnológicas destinadas, sobre todo, al profesional del audiovisual.

Básicamente lo primero que hay que tener en cuenta para la realización del Storyboard es el formato. Suelen representarse en distintos diseños que van desde los más sencillos hasta los más complejos. He aquí uno de cada caso:

La imagen del vídeo se dibuja en el espacio en blanco y en las líneas se señala el tipo de plano y el diálogo o la acción.
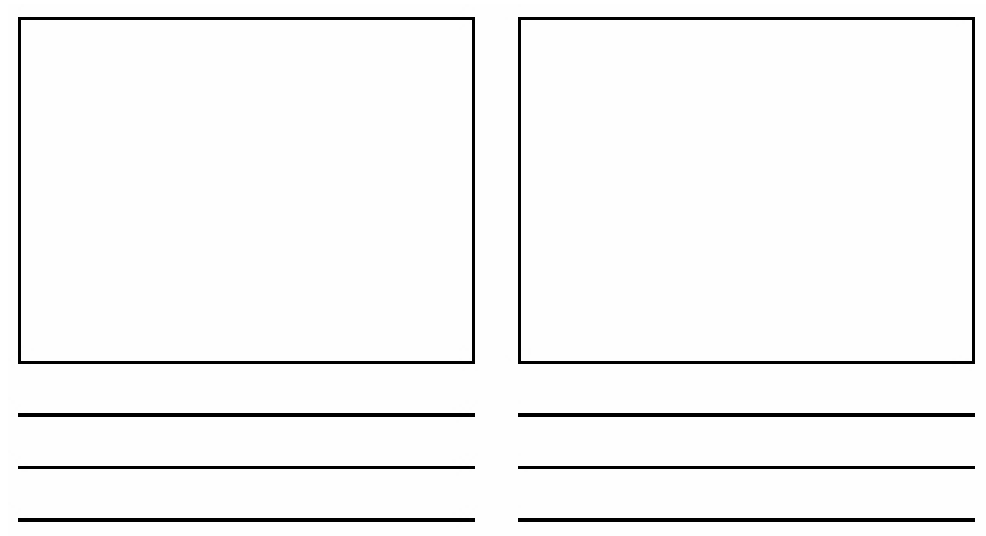

Figura 1. Tipo de viñeta para crear un storyboard.

En este otro tipo de formato, más profesional, se indica la secuencia y la duración en los dos recuadros de arriba. El número de plano debe señalarse dentro del círculo y finalmente se detalla el diálogo y el tipo de sonido o música en los recuadros enmarcados de abajo. 

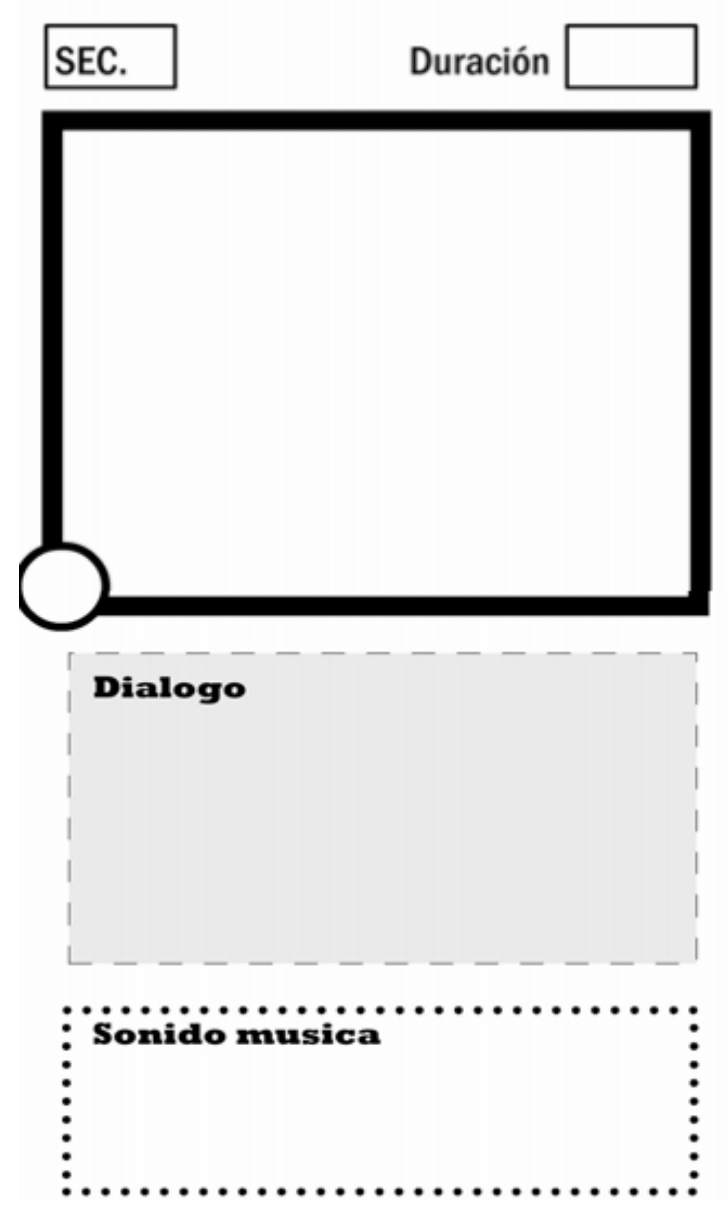

Figura 2. Otro tipo de viñeta para crear un storyboard.

Un segundo asunto por considerar es el conocimiento de la taxonomía de planos. Normalmente utilizamos la cámara para que el niño practique cada uno de los distintos planos y movimientos y los diferencie antes de diseñar el Storyboard. Un ejemplo lo podemos encontrar en Los secretos de la tele. Una guía para la alfabetización televisiva de niños y maestros (Sánchez Carrero y Martínez López, 2009), donde aparecen cada uno de los planos y movimientos de cámara explicados con un lenguaje acorde al niño como lector y un CD interactivo donde las imágenes cobran movimiento.

Y el tercer componente a tomar en cuenta es el tipo de contenido que el niño expresará gráficamente. La experiencia nos dice que una buena idea para iniciarlos en el diseño del Storyboard, es la realización de guiones de corta duración como los publicitarios. Los spots de televisión suelen ser convenientes tanto para crear como para analizar críticamente e identificar el beneficio del producto, que debe quedar claro en su propuesta. Se trata de un género muy provechoso por la diversidad de formatos que se extiende desde los anuncios más tradicionales hasta las más inimaginables iniciativas innovadoras para dar a conocer un producto en distintas plataformas digitales. 
La fase evaluativa del Storyboard incluye el análisis por separado de las imágenes que se convertirán en vídeo- y del texto. Una vez que verifiquemos que no existe un exceso de uso de imágenes o redundancia entre el vídeo y el texto, se procede a examinar la conveniencia del tipo de plano o movimiento de cámara escogido para expresar la acción. También es importante que en la continuidad de las escenas del Storyboard no exista ningún vacío para evitar confusiones a la hora de llevar a cabo la producción.

El resultado final debe transmitir una historia fácilmente comprensible, con un lenguaje sonoro que ayude a la acción y sin abundancia de efectos especiales injustificados.

\section{ANÁLISIS Y DISCUSIÓN}

Tal como afirmó Mark Prensky en el 2001: "Our students have changed radically. Today's students are no longer the people our educational system was designed to teach" (Prensky, 2001, p.1). La razón es que están creciendo con los medios digitales, de ahí que algunos les llamen Generación N (de Net) o Generación D (de digital). Pero una gran mayoría los reconoce por el epíteto de Nativos Digitales. Según este concepto los niños conviven con los medios de producción digitales, les gusta crear, jugar con los nuevos dispositivos, tejen redes con fines socializadores y aprenden en la Red y de la Red. En otras palabras, están desarrollando una identidad digital.

No obstante, el niño no nace aprendido. Estamos comenzando a entender que hay que enseñarle el uso de los medios digitales para que aprenda a utilizarlos de una manera positiva y adecuada. Es aquí donde entra en acción la educación mediática, necesidad ya reconocida por el Parlamento Europeo desde el año 2008.

The skills related to media literacy can be summarised in four areas of ability, access, analysis, evaluation and creative production. All of these skills boost aspects of personal development: consciousness, critical thinking and problemsolving abilities (Varis, 2010, p. 78).

La alfabetización mediática ofrece distintos recursos que con frecuencia utilizamos los profesionales del medio y que son excelentes para las primeras fases educativas en la comprensión de la construcción del medio audiovisual. Tal es el caso del Storyboard.

El Storyboard es un recurso gráfico que cumple una función organizativa en el proceso de la producción audiovisual. Constituye una importante ayuda a la hora de ordenar cronológicamente los hechos que van a aparecer en el documento audiovisual final. Suele utilizarse sobre todo en la producción cinematográfica (largometrajes y cortometrajes) y en la industria publicitaria. Su origen se atribuye a uno de los animadores de la industria Disney, Webb Smith, quien en la década de los 30, dibujó las escenas en páginas de papel separadas y las situó en un tablero para contar a todos su historia en secuencias. 
En nuestra opinión, en el terreno de la educación el Storyboard ofrece diversas ventajas para la comprensión de la narrativa audiovisual tanto de su forma como de su contenido.

a) Simboliza un puente entre lo escrito (el guión) y lo audiovisual (el plano).

b) Facilita la captación del lenguaje audiovisual (vídeo + sonido).

c) Evita cometer posibles errores no previstos en el guión, ya sea en el texto o en la elección de los planos de cámara.

d) Es un recurso útil para la medición previa del tiempo que durará la producción.

e) No requiere mayor inversión y ahorra tiempo y dinero de cara a la producción real.

f) Es una actividad que puede realizarse individualmente o en grupo.

g) Permite el desarrollo de la creatividad.

En el caso de los niños hay que agregar una ventaja adicional: suele ser una tarea divertida en la que ellos desarrollan su creatividad iniciando un importante proceso para el mundo audiovisual: pensar en imágenes. En la actualidad se están comenzando a conocer diversas experiencias del uso específico del Storyboard en distintos niveles de la del medio audiovisual, la mayoría prácticas aisladas del currículo escolar. Citamos algunos ejemplos:

Si miramos al sur de América Latina encontraremos una escuela que desde la década de los 80 utiliza este recurso con niños de distintas edades: el Taller El Mate. Su directora afirma que cuando los niños finalizan el guión literario los transforman en un guión visual o Storyboard. Luego, graban cada uno de los cuadros de la historia cumpliendo con los tiempos señalados en el guión e incluso representando los sonidos y los diálogos.

Es lo equivalente a una «pre-película» para que los niños tengan una idea más concreta de lo que van a grabar cuando enfrenten la producción. Una vez finalizada, se procede al visionado con el fin de solventar las dificultades que se puedan presentar en la realidad (Sánchez-Carrero, 2008, p.117).

En Girona (España) recordamos una curiosa práctica con alumnos muy pequeños con quienes se inició un programa educativo fílmico digital para primaria. Durante más de 2 meses instruyeron a niños de 4 años de edad en el proceso de producción de una película. El primer paso fue, lógicamente, la elaboración de un Storyboard con la historia que tenían en su mente. Esto facilitó la posterior grabación y edición del vídeo (Pinós, 2004).

En Estados Unidos existe ya cierta experiencia en el uso de storyboards en la enseñanza primaria. Según Andrews (2009) los estudiantes pueden aprender más fácilmente a leer y a escribir, plasmar sus ideas en papel y luego identificar qué palabras son las mejores para su historia les beneficia notablemente. Constituye una valiosa herramienta para el maestro al momento de llevar a cabo un proyecto 
audiovisual puesto que en lugar de centrarse sólo en las palabras, puede utilizar la imagen para mostrar lo que está sucediendo en una escena. Esto permite a los alumnos un recurso más para expresar sus ideas cuando se trabaja en grupo.

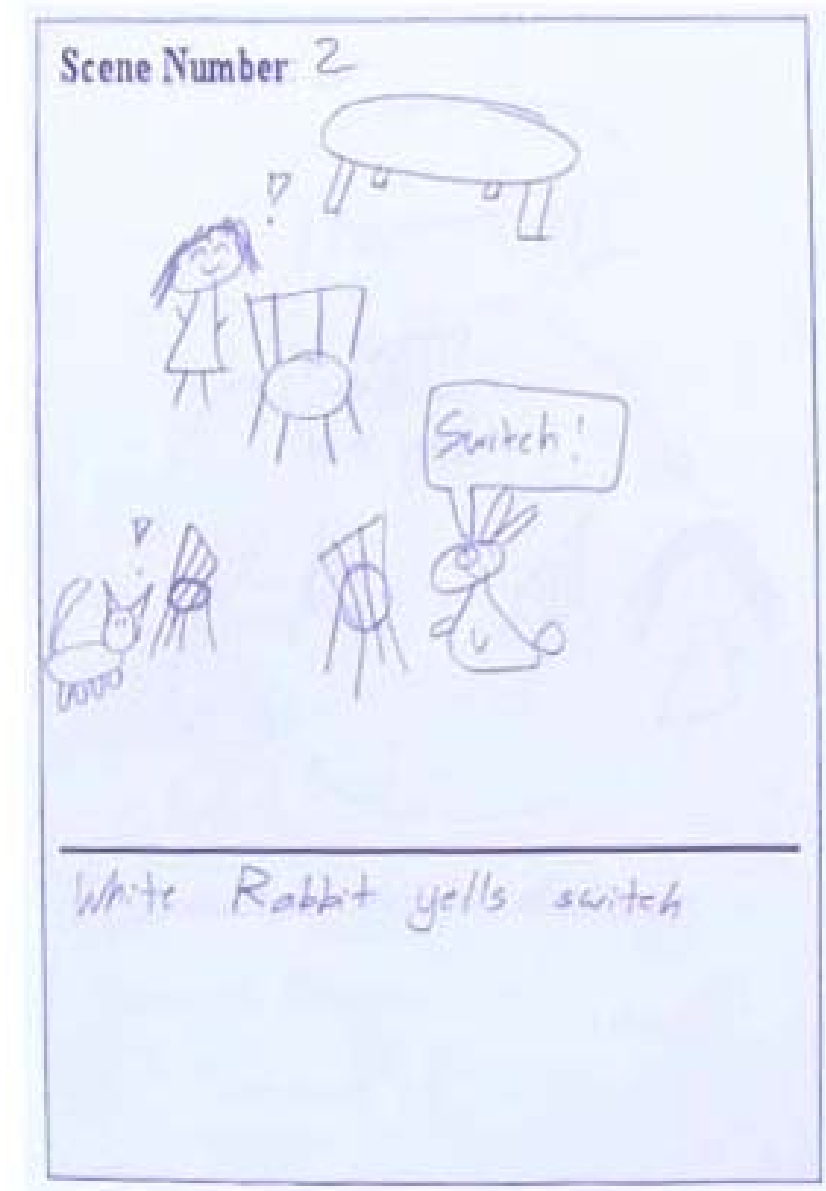

Figura 3. Ejemplo de storyboard en la fase "continuación de la historia" según la experiencia como maestra de Tammy Andrews (2009).

En grupos adolescentes también se está promoviendo actualmente la utilización del vídeo digital previo el uso del storyboard. En una de sus investigaciones David L. Bruce - de la Universidad de Búfalo (EEUU)- revela sus logros dentro de un programa de educación para profesores con el fin de conocer qué ocurre cuando los estudiantes trabajan con un medio como el audiovisual. La tarea asignada fue componer un vídeo relativo a un poema escrito, al que llamaron «cinepoema». La idea era interpretar un poema a través de una elección determinada de imágenes.

El uso del storyboard fue el eje a través del cual comenzaron a girar las ideas para la composición audiovisual. A pesar de que hubo viñetas que no pudieron grabarse exactamente igual por problemas logísticos que impidieron registrar las secuencias como las habían imaginado, el grupo se acercó bastante a la idea inicial. Podemos reconocer en el gráfico de abajo que muchos de los planos diseñados se cumplieron tal como estaba previsto, son muy similares. En este caso el storyboard sirvió como plantilla visual para su vídeo final. 


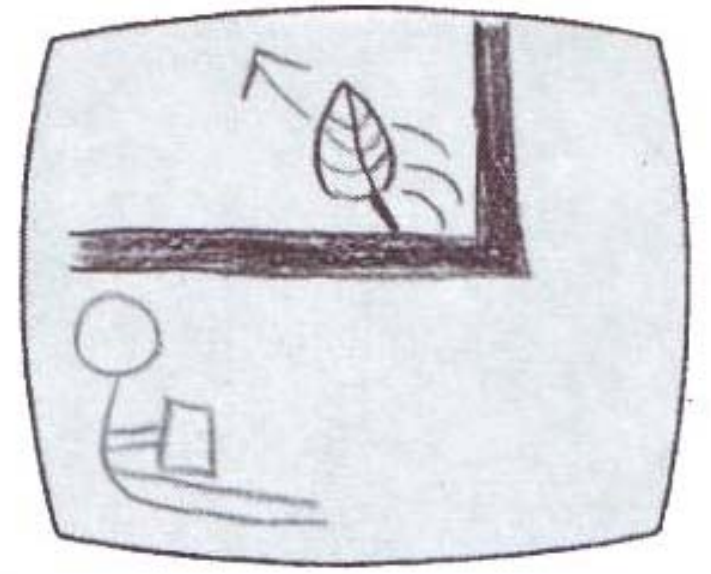

Figure 5.12 Storyboard of sequence 9

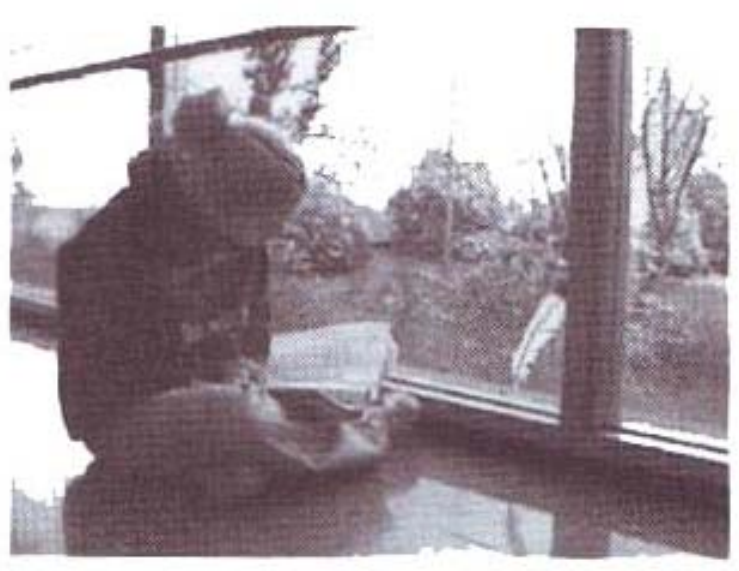

Figure 5.13 Video still of sequence 9

Figura 4. Gráfico tomado de: David L. Bruce (2010) Composing and Reflecting. Integrating Digital Video in Teacher Education.

Una de las ventajas que observó Bruce fue las características heurísticas de los adolescentes, es decir, su capacidad para realizar de forma rápida acciones innovadoras positivas para lograr el objetivo propuesto (Bruce, 2010). El storyboard sirvió, indudablemente, como uno de los elementos motivadores de dichas acciones.

Desde Londres (Inglaterra) Burn y Durran hacen referencia a otro interesante proyecto Media literacy: creative production en el cual el niño adquiere cambios significativos al pertenecer activamente a grupos de trabajo donde aprenden a negociar, a resolver problemas y a cooperar. Ellos asumen el rol del productor y elaboran el storyboard para sus películas. Esto suele ser especialmente útil en la asignatura de Ciencias, puesto que al grabar cada paso del método científico, obtienen una explicación visual -no sólo teórica- acerca del descubrimiento que están logrando. Es decir, el proceso favorece sus conductas experimentales en este campo. Los autores señalan que quizás lo más importante de la experiencia es la alta motivación que alcanza el niño y la obtención de distintos estilos de aprendizaje y desarrollo de la inteligencia (Burn \& Durran, 2007).

Veamos ahora las características que hemos encontrado en nuestros trabajos en los que los niños desarrollan el proceso de producción de sus propios documentos audiovisuales.

\subsection{Descripción del storyboard infantil}

"El storyboard infantil es aquel que ha sido diseñado y creado por la mano de un niño o grupos de niños y que está inspirado en ideas propias" (Sánchez-Carrero, 2008b, p. 4). En nuestra experiencia de talleres audiovisuales infantiles, desarrollados tanto en Venezuela como en España desde hace más de una década, hemos detectado la importancia que da el niño a su pequeña obra; por ello toda expresión plasmada en el 
storyboard es respetada interviniendo únicamente en el caso de ideas imposibles de realizar. La finalidad de todo storyboard es que la historia sea coherente con el objetivo planteado y, naturalmente, que sea comprensible por todo tipo de público. En el caso de los niños valoramos su creación que frecuentemente tiene toques de fantasía.

Consideramos que se trata de una estrategia creativa provechosa por cuatro razones fundamentales:

a) Logra que el niño piense en imágenes

b) Facilita la comprensión de la continuidad en el audiovisual

c) Permite imaginar la puesta en escena

d) Fija la teoría de los planos y su significado

En la práctica, el uso del storyboard se presenta como una dinámica educativa de fácil acceso y entendimiento. Basta con dibujar en un folio el formato típico de cómic con varios cuadrantes, o si se prefiere, el formato clásico de dos columnas una -la de la izquierda- destinada a la imagen y otra -a la derecha- para el sonido. Luego animar al niño a jugar con su imaginación y componer pequeñas historias. El hecho de organizar las imágenes en secuencia le ayudará a encadenar la idea principal del mensaje utilizando la lógica, mientras que la selección de planos y de sonidos (audio, música y efectos) aportará el sentido final de la situación creada que debe de ser entendida por todos. 


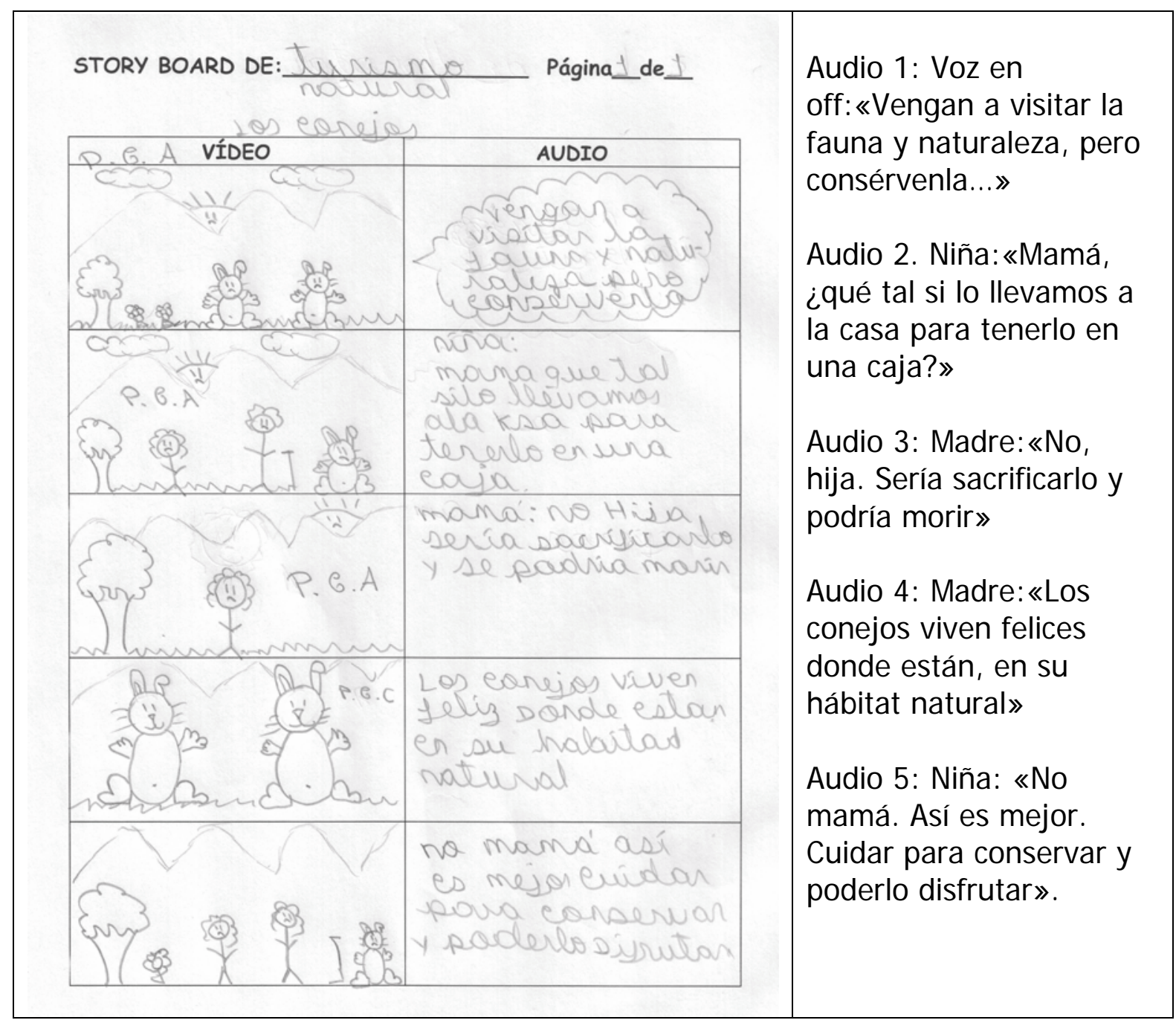

Figura 5. Ejemplo de 'storyboard' realizado por los niños.

El siguiente es el storyboard realizado para una campaña de Turismo en el Estado Mérida (Venezuela), durante el Taller Telekids impartido en agosto de 2010.

Su autora es Maylena, una niña de 10 años, quien hizo hincapié en reflejar su sensibilidad hacia los animales. Se puede observar la utilización de los planos generales abiertos -según nos comentó- para disfrutar del panorama, y de la indicación del bocadillo -utilizado más en el mundo del cómic- para señalar la voz en off.

En el campo de la publicidad los niños parecen manejarse mejor que ante otros géneros audiovisuales. Tiene mucha información que sus familiares les comunican en lo poco o mucho que comparten el visionado televisivo. Veamos dos ejemplos de storybard publicitario el primero del año 2009 y el segundo del 2005. El primero es el de Carmen, una niña española de 10 años, que decidió hacer su Storyboard con la promesa publicitaria de hacer realidad los sueños. El producto elegido por el grupo fue Coca Cola. 

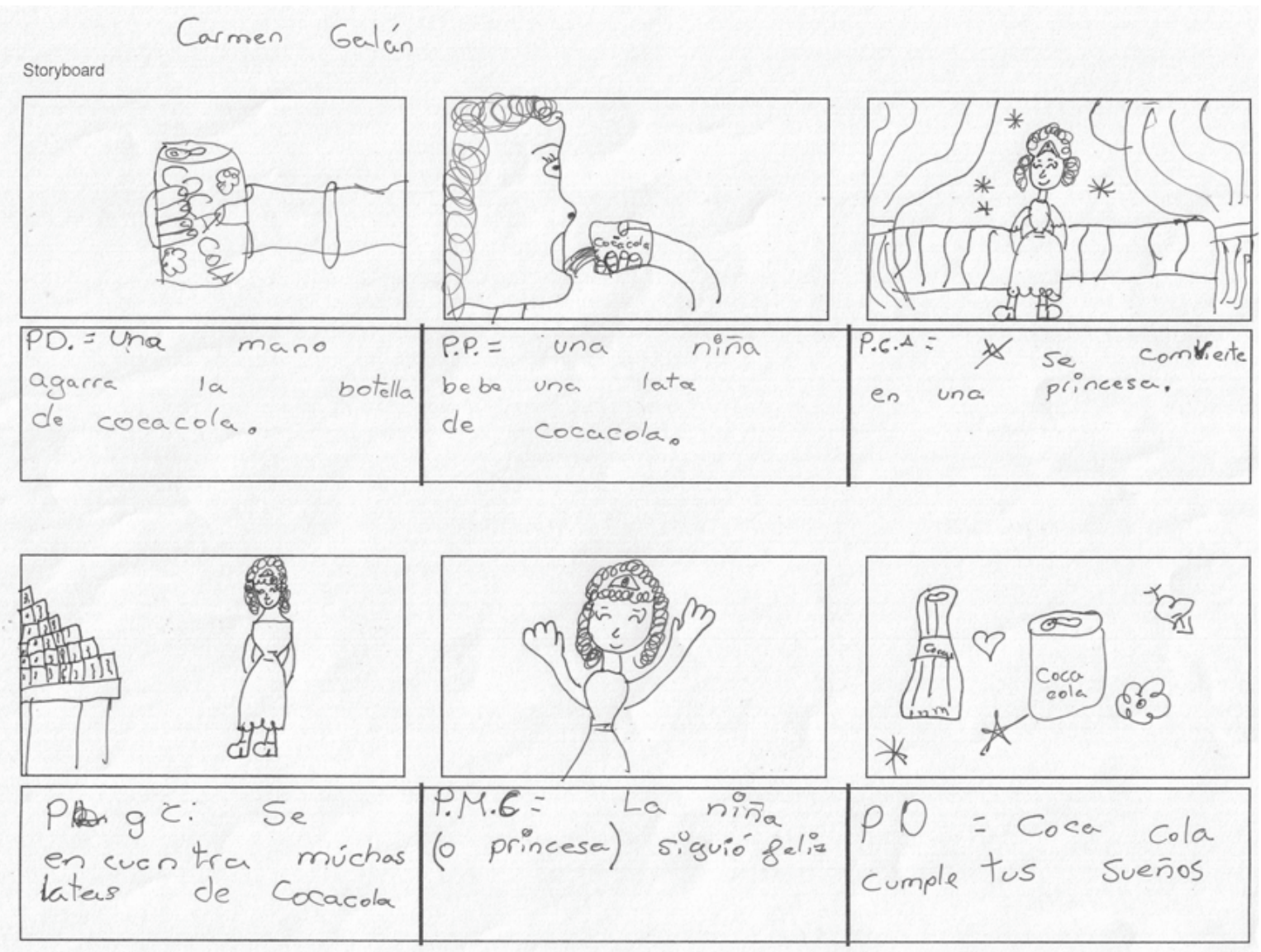

Figura 6. Otro ejemplo de 'storyboard' realizado por los niños.

1.- Plano Detalle: Una mano agarra la botella de Coca Cola (es más bien una lata)

2.- Primer Plano. Una niña bebe una lata de Coca Cola

3.- Plano General Abierto. Se convierte en una princesa.

4.- Plano General Cerrado. Se encuentra muchas latas de Coca Cola

5.- Plano Medio Cerrado. La niña (o princesa) siguió feliz

6.- Plano Detalle: Coca Cola cumple tus sueños.

En esta ocasión recordamos que el grupo finalizó el diseño del Storyboard rápidamente, hecho que atribuimos al agrado que sentirían por la bebida refrescante. Sin embargo, muchos confesaron que sus padres no les permitían beber Coca Cola aún o simplemente que no les gustaba. Lo que sí conocían desde hace tiempo eran los spots de televisión y comprendían que la publicidad consiste en vender un producto les gustara o no. 


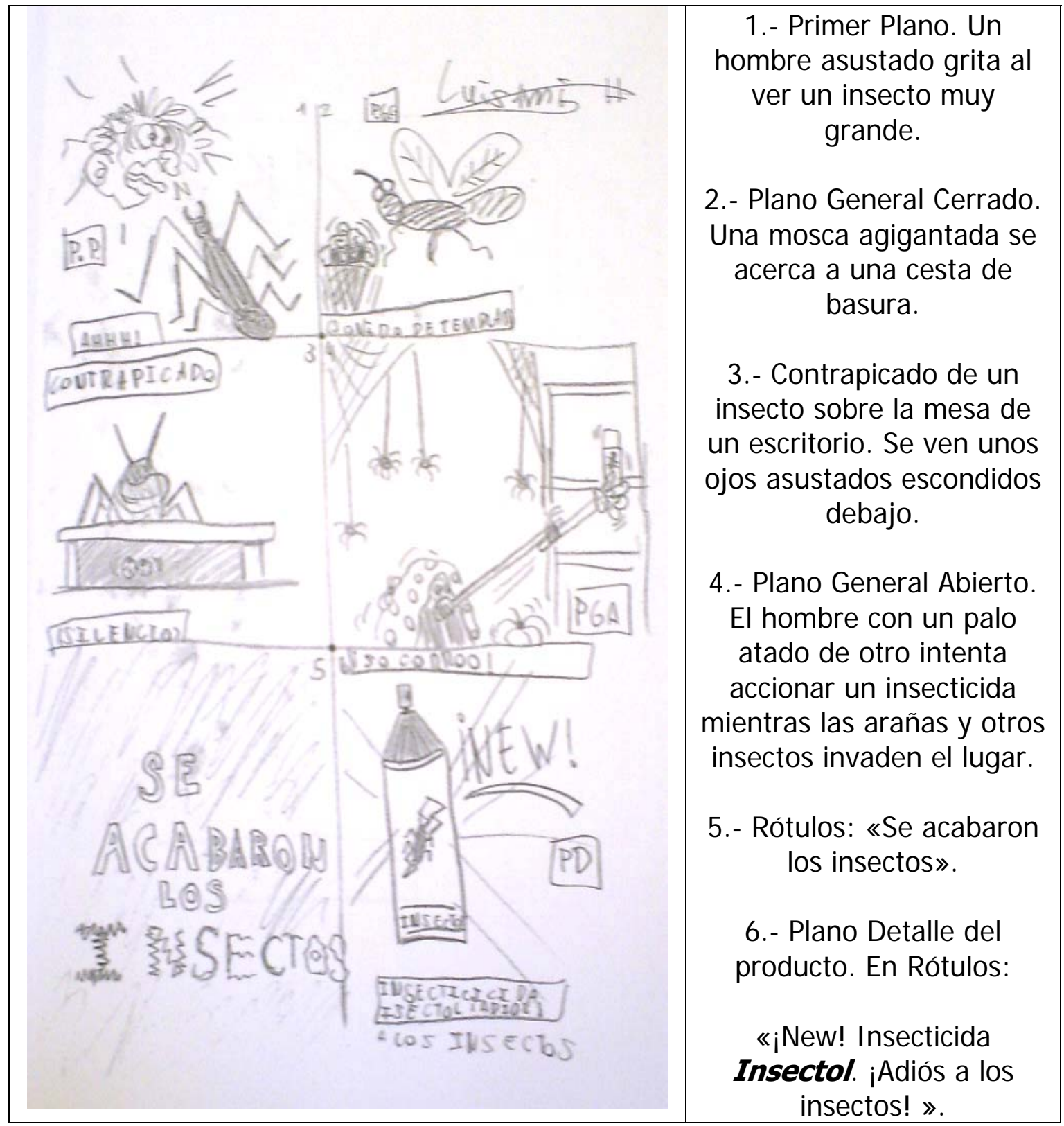

Figura 7. Ejemplo de la llamada «mirada de cámara»

Este fue el trabajo de Luis Miguel, un niño español de 11 años con facilidades para dibujar y poseedor de la llamada «mirada de cámara». En los planos 3 y 4 podemos observar la situación que da al hombre protagonista del anuncio. En el primero está debajo del escritorio enfocado con un plano contrapicado y en el segundo se puede ver por debajo de la sábana, mientras utiliza el insecticida. En el cuadro final destaca el producto y usa el plano detalle y la palabra inglesa «new», según dijo, para llamar la atención del consumidor.

Pudimos observar que la publicidad es uno de los espacios audiovisuales más vistos por los menores en la televisión. Concordamos con Bazalgette cuando afirma: 
Los niños y niñas aprenden a reconocer e interpretar los dispositivos retóricos específicos de los medios que presentan imágenes en movimiento. Es un hecho importante, porque se indica un proceso de aprendizaje sobre un sistema retórico que está jugando un papel significativo en nuestra cultura².

Otra pregunta que surge con frecuencia es la edad en que los chicos pueden diseñar realmente un Storyboard. En la mayoría de los casos los niños alrededor de los 8 años ya son capaces de formar y expresar una idea secuencial de una historia determinada. Los niños de edades menores, en un nivel preescolar, tal vez no desarrollen la idea completa pero sí logran distinguir e identificar las partes principales de un cuento infantil (planteamiento-nudo-desenlace), en ocasiones con un poco de ayuda para dar prioridad a los hechos. Sin embargo, las escenas no dejan de ser trazos con algunos vacíos de contenido. Es alrededor de los 8 años aproximadamente cuando son capaces de ordenar una secuencia audiovisual y elegir planos adecuados de cámara.

En resumen, el Storyboard realizado por niños se caracteriza por ser imaginativo, puesto que plasma en él la representación tanto de su realidad como de sus sueños; es minucioso, suele incluir detalles en los dibujos lo cual es beneficioso sobre todo para el Storyboard publicitario; tiene una mirada positiva de la situación, aunque eso depende del objetivo que se trace en el proyecto audiovisual. Quizás la dificultad que más encuentran está en la limitación de planos que utilizan: planos generales abiertos o cerrados, primer plano y plano detalle, dejando de lado los movimientos de cámara. Otro obstáculo suele estar en la comprensión de la continuidad narrativa, la secuencialidad. De ahí que sea importante escribir la historia -un pequeño guión escrito- antes de iniciar el Storyboard y así definir los puntos clave del flujo visual narrativo.

\section{CONCLUSIONES}

En los últimos años hemos visto la proliferación de programas de ordenador que ayudan a los profesionales del audiovisual en el diseño del Storyboard. Entre ellos podemos destacar Storyboard examples (Power Production Softwares) que posibilita la construcción de guiones gráficos destinado al mundo de la educación. Facilita el diseño de personajes, la organización de las ideas que se quieren transmitir y la selección de planos según la intención del director. Otras versiones profesionales del mismo software incluyen la previsualización digital de la escena final.

Recapitulando, construir una historia en imágenes suele ser una acción recreativa para los niños, puesto que utilizan una serie de viñetas que guardan relación con un formato ya conocido por ellos como es el cómic. Aunque en algunos casos el Storyboard infantil presenta pequeños errores de carácter técnico 0 ideas disparatadas, lo cierto es que sorprenden en su forma de expresión y de disponer los elementos narrativos en un documento audiovisual. Se trata de una estrategia educativa para la mirada en materia audiovisual que ha de ser reconocida y

\footnotetext{
${ }^{2}$ Entrevista realizada a Cary Bazalgette a propósito del Foro Mundial de la TV Infantil efectuado en Barcelona en noviembre de 2008.
} 
aprovechada. Hoy en día hasta los jurados de los festivales de cine para niños están valorando la técnica del Storyboard como complemento al desarrollo del guión.

Finalmente, es trascendental recordar que detrás de todo este uso de recursos para la producción audiovisual está la educación en medios. Nuestro objetivo más amplio, como educomunicadores, ha sido y es involucrar a los niños en el estudio del universo audiovisual de un modo crítico y creativo.

El desafío no se reduce sólo a proporcionar criterios e instrumentos para que la niño, el niño o el joven puedan posicionarse críticamente frente a los medios, se trata además de comprender que los medios contextualizan y en muchos casos determinan las maneras en que las personas ejercen sus derechos en los planos cultural, político, económico y social (Opertti, 2009, p. 31).

Se trata entonces de "formar alumnos competentes en el uso de los nuevos lenguajes, y consecuentemente, más críticos y creativos con su entorno, conscientes de su realidad, capaces de actual libre, autónoma y juiciosamente" (Aguaded, 2010, p. 57). Ciertamente, estamos frente a un reto que hemos de superar y es conseguir la implantación sistemática de la Media Literacy desde los primeros niveles educativos. Esto contribuiría al desarrollo de las competencias comunicativas de los ciudadanos en una sociedad que navega cada vez con las nuevas tecnologías de la información y la comunicación.

\section{REFERENCIAS}

Aguaded, I. (2010). La educación para la comunicación. Nueva alfabetización para un mundo global, en Del Moral, E. Televisión: desarrollo de la creatividad e infancia ( $p$. 55-70). Barcelona: Octaedro.

Andrew, T. (2009). Using Storyboards in the Classroom. Consultado el 19 de Septiembre del 2010, Disponible en: www.suite101.com/content/using-storyboards-inthe-classroom-a129583

Bazalgette, C. (2008). British Film Institute (BFI) 1979-2007, en Revista Anual Paideia, no 10, p. 22.

Burn, A. y Durran, J. (2007). Media Literacy in Schools. Practice, production and progression. Londres: Sage Publication.

Opertti, R. (2009). Aportes curriculares para la educación en medios: un proceso en construcción, en Revista Comunicar, no 32, p. 31.

Bruce, D. (2010). Composing and Reflecting. Integrating Digital Video in Teacher Education, en Tyner, K. Media Literacy. New Agendas in Communication. Texas: Routledge. (p. 32) 
Pinós, C. (2004). Días Digitales. Una visión del uso del vídeo digital con clases de primaria, en Making off. Cuadernos de Cine y Educación, oㅡ 29, p. 29-33.

Sánchez-Carrero, J. \& Martínez-López, E. (2009). Los secretos de la tele. Una guía para la alfabetización televisiva de niños y maestros. Sevilla: Aconcagua.

Sánchez-Carrero, J. (2009b). Garabatos en un Storyboard: los primeros pasos para comprender la narrativa audiovisual, en Revista Admira Online, ํo 1.

Sánchez-Carrero, J. (2008). Pequeños directores. Niños y adolescentes creadores de cine, vídeo y televisión. Sevilla: Aconcagua.

Varis, T. (2010). Understanding Media Literacy, en Carlsson, U. (Ed.) Children and Youth in the digital media culture. From a Nordic horizon. Gotemburgo: Nordicom ( $p$. 78).

Jacqueline Sánchez Carrero 